\begin{tabular}{|c|}
\hline ARTIGO \\
Recebido \\
em: \\
26/09/2017 \\
\\
Aceito em: \\
28/11/2018 \\
\hline
\end{tabular}

\section{Escolarização, Capital Cultural e Competência em Informação: reflexões acerca do envolvimento da tríade no desenvolvimento social dos sujeitos}

\author{
Schooling, Cultural Capital and Information Literacy: reflections about the \\ triad's involvement in the subject's social development
}

\begin{abstract}
Resumo
É por meio da capacidade de aprender a aprender, do conjunto de habilidades que constitui o processo de competência em informação que se pode aproveitar o potencial de circulação de informações dentro e fora da web. Entretanto, um prévio acesso a recursos escolares, culturais e informacionais torna-se indispensável. De natureza bibliográfica e exploratória, este artigo aborda as relações entre o conjunto de capitais potencialmente acumulados pelos sujeitos ao longo de sua trajetória, seu processo de escolarização e a capacidade de se tornar "competente" no uso de informações e conhecimento. Para tanto, o referencial teórico fundamenta-se nos Estudos Sociais da Ciência e da Informação de forma analisar processos sociais e informacionais como os de "Capital Cultural" e "Competência em Informação", que estariam intrinsecamente envolvidos no acesso competente à informação. A conclusão é a de que esses processos desenvolvidos pelas pessoas são determinantes no uso efetivo de fontes confiáveis de informação, promovendo autonomia no desenvolvimento de conhecimentos e contribuindo para o desenvolvimento social dos cidadãos.

Palavras-chave: Capital Cultural. Competência em Informação. Escolarização. Desenvolvimento Social.
\end{abstract}

\begin{abstract}
It is through the ability to learn to learn, from the set of skills that constitute the process of information literacy that one can take advantage of the potential of circulation of information inside and outside the web. However, prior access to school, cultural and information resources becomes indispensable. Of a bibliographical and exploratory nature, this article discusses the relations between the set of capitals potentially accumulated by the subjects along their trajectory, their schooling process and the ability to become "competent" in the use of information and knowledge. For this, the theoretical framework is based on the Social Studies of Science and Information to analyze social and informational processes such as "Cultural Capital" and "Information Literacy", which would be intrinsically involved in the competent access to information. The conclusion is that these processes, acquired and developed by the subjects, are determinant in the effective use of reliable sources of information, promoting autonomy in the acquisition of knowledge and contributing to the social development of the citizens.

Keywords: Cultural Capital. Competence in information. Schooling. Social development.
\end{abstract}

v. 24, n. $54,2019$. p. $14-24$

ISSN 1518-2924 


\section{INTRODUÇÃo}

A internet, inegavelmente, tornou-se uma importante fonte de informação contemporânea. Dados da pesquisa Indicador de Letramento Científico realizada pelo Instituto Abramundo, em 2015, com 2.002 entrevistados de 15 a 40 anos, indicam que a internet representa, para os americanos, a principal fonte de informação sobre temas científicos específicos como mudança climática, biotecnologia e temas ligados à saúde e medicamentos (GOMES, 2015).

Entretanto, ainda não é possível afirmar que há uma completa democratização do acesso ao conhecimento no universo da web: o Relatório sobre o Desenvolvimento Mundial 2016: dividendos digitais, realizado por uma equipe do Grupo Banco Mundial, mostra que as mudanças tecnológicas trazidas pela internet não aumentaram as oportunidades econômicas, como previsto, e as pessoas que possuem níveis financeiros e educacionais mais altos são as que melhor conseguem aproveitar as oportunidades oferecidas pela internet. Ainda segundo a pesquisa, apenas ampliar o acesso à internet não é suficiente para sanar as desigualdades, sendo necessário, entre outras medidas, o investimento em habilidades que promovam um efetivo acesso dos cidadãos às oportunidades geradas pela internet.

Nesse sentido seria possível afirmar que cidadãos "habilidosos" no uso da internet seriam capazes, entre outras ações, de aperfeiçoar seus processos de busca e uso das informações, reconhecendo critérios que possam determinar o nível de confiabilidade de uma fonte de informação na web. Porém, mais do que competência tecnológica, é provável que esse processo esteja envolto em questões sociais mais profundas tais como o capital cultural desses sujeitos e o desenvolvimento de suas habilidades na busca, análise e uso de informações, processo que compõe sua competência em informação e, assim como o capital cultural, relaciona-se à possibilidade de acesso a equipamentos culturais e educacionais como escolas e bibliotecas.

Este artigo objetiva refletir sobre o desenvolvimento da competência em informação. Por meio de pesquisa bibliográfica, visa-se a ressaltar a existência da tríade Escolarização, Capital Cultural e Competência em Informação como elementos de influência no processo de desenvolvimento social dos sujeitos. Além desta introdução, o artigo traz algumas reflexões sobre o conceito de competência em informação, sobre o papel da escola e da biblioteca no processo de desenvolvimento de competência em informação e sobre o conceito de Capital Cultural de Bourdieu.

\section{COMPETÊNCIA EM INFORMAÇÃO: REFLEXÕES}

O conceito de competência surge no campo empresarial e financeiro com o objetivo de melhorar a produtividade e a competitividade do trabalho humano em decorrência do processo de substituição tecnológica. No âmbito educativo, a ideia de transposição dos conteúdos do "mundo do trabalho" para o currículo escolar possui a intenção de superar a lacuna existente entre os conhecimentos propiciados pela escola e aqueles requeridos no mercado de trabalho. Nesse sentido, a noção subjacente ao conceito de competência é a aplicação prática do conhecimento (GASQUE, 2012).

Para Perrenoud (2000), competência designa a capacidade de mobilizar diversos recursos cognitivos para enfrentar situações específicas. 0 exercício da competência envolve operações mentais complexas que permitem realizar ações adaptadas à situação. Isso significa que as competências podem ser construídas também através das experiências do cotidiano.

0 processo de competência pode designar ainda uma mobilização mais imediata ou mais reflexiva, dependendo da situação. Há sempre uma mobilização de conhecimentos que orienta o indivíduo a agir em determinada situação. Se há exigência de uma ação imediata, o sujeito se ampara nos conhecimentos presentes em sua memória naquela ocasião; entretanto, para que o saber oriente a ação, é necessário maior tempo para que o indivíduo possa raciocinar, relacionar e organizar informações (PERRENOUD, 2001).

Sendo assim, para Gasque (2012, p. 36), "propõe-se que competência seja utilizado como expressão do 'saber fazer', derivada das relações entre o conhecimento que o sujeito detém, a experiência adquirida pela prática e a reflexão sobre a ação". As habilidades decorrem das competências adquiridas. Se a competência a ser desenvolvida relaciona-se ao acesso efetivo à informação, por exemplo, as habilidades prováveis seriam selecionar os métodos adequados de pesquisa ou sistemas de recuperação, planejar estratégias de busca de informação e recuperar dados em sistemas de informação. Esse conjunto de habilidades refere-se à competência em informação.

A "sociedade da informação" é o espaço mais abrangente por onde trafega o movimento da competência em informação. Conforme Campello (2003, p. 33),"é um ambiente tão diferente e mutante que exige novas habilidades para nele se sobreviver".

Nesse sentido, segundo Ford (1994, on-line, tradução nossa) a "competência em informação prepara o indivíduo para tirar vantagem das oportunidades inerentes à sociedade da informação 
globalizada. A competência em informação deveria ser parte de toda experiência educacional dos estudantes".

No que tange ao ensino, Le Coadic (1996) frisa que muitas pessoas são pesquisadoras medíocres em informação e que a introdução da disciplina "informação", seria a garantia para o ingresso dos alunos na sociedade da informação.

Se a sociedade da informação é ambiente de abundância informacional, a tecnologia é o instrumento que vai permitir lidar com o problema. Entretanto, há também uma preocupação em mostrar que a fluência em tecnologia é só uma parte do processo de competência em informação (CAMPELLO, 2003).

Segundo a American Library Association (ALA, 2000, p. 3, tradução nossa), a fluência tecnológica é considerada "uma estrutura intelectual para compreender, encontrar, avaliar e usar informação atividades que podem ser realizadas em parte através da fluência em tecnologia, em parte através de métodos de pesquisa sólidos, mas principalmente através de discernimento e raciocínio."

Sobre a questão tecnológica, Tarapanoff, Suaiden e Oliveira (2002) salientam que não poderá haver sociedade da informação sem cultura informacional. Para os autores, estar bem informado é essencial para se exercer a cidadania, e ainda complementam que o maior problema da inclusão digital não é a falta de computadores, mas o analfabetismo em informação.

$\mathrm{Na}$ contramão do analfabetismo, a alfabetização em informação deve criar pessoas capazes de encontrar, avaliar e usar informação de maneira eficaz para resolver problemas ou tomar decisões. Uma pessoa alfabetizada em informação seria aquela capaz de identificar uma necessidade informacional, organizá-la e aplicá-la na prática, agregando-a a um corpo de conhecimento de modo a resolver problemas (SILVA et al., 2005).

Segundo Fialho e Moura (2005, p. 197), a competência em informação

abarca processos de pensamento e habilidades interpessoais e implica distintas áreas da aprendizagem, que capacitam uma pessoa a: saber quando precisa de informação, identificar a natureza e extensão da informação solicitada para solucionar um problema determinado, aplicar estratégias que permitam encontrar a informação necessária (conhecimento e utilização dos recursos de informação, assim como avaliar sua utilidade, confiabilidade e qualidade), avaliar de forma crítica a informação e sua relevância para o assunto que se pretende resolver, analisar/organizar e comunicar a informação de acordo com os objetivos específicos, aplicar a informação de forma efetiva para solucionar um problema determinado, determinar a relação custo/ benefício de obter e acessar a informação (tempo e dinheiro) e entender os aspectos econômicos, legais e sociais relacionados com o uso da informação, utilizando-a de forma ética e legal.

Os documentos institucionais sobre competência em informação mencionam as habilidades essenciais para se sobreviver na sociedade da informação: habilidade de solucionar problemas, de aprender independentemente, de aprender ao longo de toda a vida, de aprender a aprender, de questionamento, de pensamento lógico, colocando-as na categoria de habilidades cognitivas de ordem superior ou de pensamento crítico (CAMPELLO, 2003).

Uma dessas instituições, a American Library Association (ALA), definiu o que seria necessário para ser competente em informação. Em tradução de Dudziak (2003, p. 26):

Para ser competente em informação, uma pessoa deve ser capaz de reconhecer quando uma informação é necessária e deve ter a habilidade de localizar, avaliar e usar efetivamente a informação. Resumindo, as pessoas competentes em informação são aquelas que aprenderam a aprender. Elas sabem como aprender, pois sabem como o conhecimento é organizado, como encontrar a informação e como usá-la de modo que outras pessoas aprendam a partir dela.

Entendendo que a competência em informação é desenvolvida também no âmbito institucional, dentro das instituições de ensino, apresenta-se na próxima seção reflexões com esse direcionamento.

3 COMPETÊNCIA EM INFORMAÇÃO E ESCOLARIZAÇÃO: PAPÉIS DA ESCOLA E DA BIBLIOTECA 
Se a competência em informação é uma metáfora relacionada ao aprendizado permanente, ligada ao processo de aprender a aprender, a educação voltada para tal competência, chamada de Information Literacy Education (ILE) é o caminho que nos leva até ela (DUDZIAK, 2003).

Em todo o mundo, novos projetos educacionais passaram a ser planejados e implementados para manter seu foco nos processos de construção de conhecimento do aprendiz, enfatizando seus conhecimentos, habilidades e valores. Uma educação de qualidade é aquela que privilegia o aprender a aprender, priorizando a atitude investigativa e uma busca criativa. Para isso, é necessário amplo questionamento em torno das políticas educacionais e dos parâmetros de qualidade educacional almejados, visando a que a informação esteja inclusa em todos os processos educacionais. A implementação de um projeto educacional voltado para a informação exige transformação nos papéis sociais e profissionais tanto no âmbito da comunidade educacional quanto perante a sociedade (DUDZIAK, 2003).

No Brasil, o surgimento dos Parâmetros Curriculares Nacionais (PCNs), em 1997, permitiram iniciar uma nova etapa do esforço federativo em premissas educacionais (SIQUEIRA, 2011).

Segundo a publicação Parâmetros Curriculares Nacionais: terceiro e quarto ciclos do ensino fundamental (1998), os PCNs foram elaborados procurando criar condições, nas escolas, que permitissem aos jovens ter acesso aos conjuntos de conhecimento socialmente elaborados e reconhecidos como necessários ao exercício da cidadania, sempre considerando as diversidades regionais, culturais e políticas existentes no país.

Sobre uma eventual política de competência em informação para escolas básicas, os PCNs descrevem os objetivos gerais para o Ensino Fundamental como "saber utilizar diferentes fontes de informação e recursos tecnológicos para adquirir e construir conhecimentos" (BRASIL, 1997, p. 69).

Para o Ensino Médio, a finalidade é o "desenvolvimento da capacidade de aprender e continuar aprendendo, da autonomia intelectual e do pensamento crítico, de modo a ser capaz de prosseguir os estudos e de adaptar-se com flexibilidade a novas condições de ocupação ou aperfeiçoamento" (BRASIL, 2000, p. 101).

Práticas curriculares como o currículo integrado (baseado na transdisciplinaridade) e o aprendizado baseado em recursos (resource-basedlearning) dão respaldo à competência em informação. 0 currículo integrado busca organizar os saberes a partir de grandes temas-problema, envolvendo atividades de busca, ordenação, análise, interpretação e representação da informação, possibilitando um aprendizado ativo e independente com o docente atuando apenas como facilitador; já o aprendizado baseado em recursos reúne variados interesses às mais variadas fontes de informação e conhecimento, de forma que o aprendizado e a estrutura curricular se adaptem aos interesses dos aprendizes, possibilitando que este tenha controle sobre seu aprendizado. Também neste caso o docente atua como facilitador (DUDZIAK, 2003).

Um dos principais instrumentos para se avaliar a habilidade que os alunos estão desenvolvendo com o uso da informação é a pesquisa escolar: por meio dela se percebem as habilidades relacionadas à busca e seleção das fontes, capacidade de se extrair ideias, de confrontá-las e de formar conjecturas entre as mesmas. Entretanto,

para desenvolver o espírito crítico e a postura científica no aluno, seriam necessárias as condições propícias[...]como, por exemplo, corpo docente qualificado, boa infraestrutura das escolas e uma proposta curricular ajustada. Tais fatores tornam este um desafio complexo e expõem a necessidade de adoção de políticas que abranjam a qualidade do ensino oferecido e de políticas internas, nas escolas, que possam ser viabilizadas através de um projeto pedagógico. (FIALHO; MOURA, 2005, p. 195).

Fialho e Moura (2005) abordam ainda o conceito de aprendizagem baseado no questionamento, que engloba teorias da competência em informação, da aprendizagem baseada no questionamento e no letramento, os quais formam um tripé cujo objetivo é tornar o aluno crítico e reflexivo, o contrário de uma atitude passiva diante da realidade. 0 professor incentiva o aluno a pensar, sendo os recursos das bibliotecas e a atividade de pesquisa indispensáveis ao processo. 


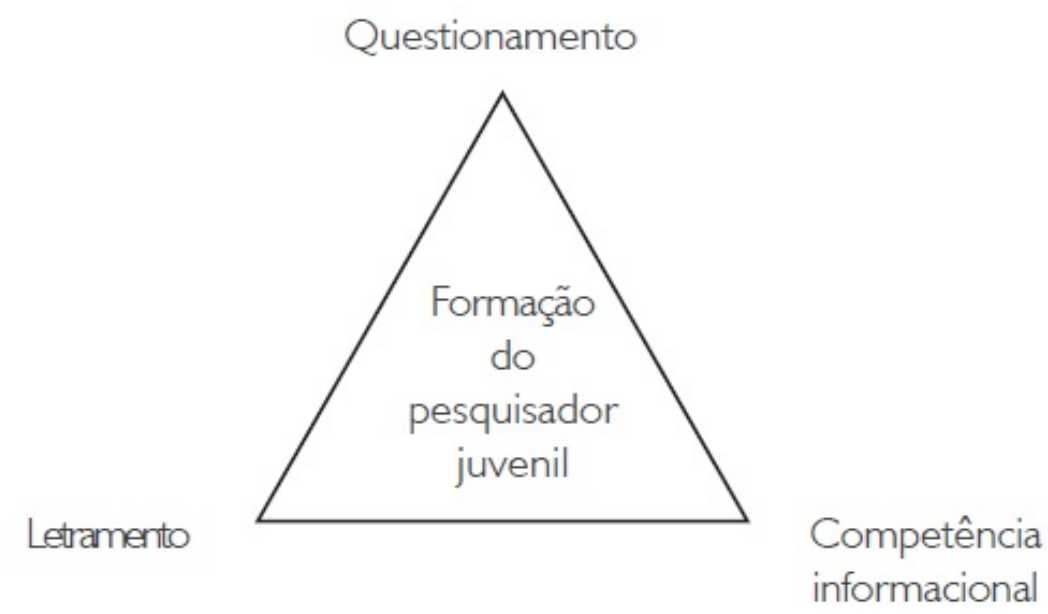

Figura1 - Aprendizagem baseada no questionamento Fonte: Fialho e Moura (2005, p. 196).

Ao fazer um trabalho de pesquisa, que é uma atividade intrínseca de aprendizagem baseada no questionamento, o aluno incorpora diversas habilidades de uso da informação, como a capacidade de dialogar com colegas e professores de forma a definir suas necessidades de informação; identificar potenciais fontes de informação, formais ou informais, de diferentes níveis e formatos; avaliar criticamente a informação segundo sua relevância, objetividade, pertinência, ética, lógica, incorporando-a ao seu próprio sistema de valores e de conhecimento; ter a capacidade de comunicar sua pesquisa individualmente ou como membro de um grupo; demonstrar atitude proativa diante do aprendizado, dentre outras. (DUDZIAK, 2003).

Outro fator envolvido no desempenho dos estudantes é a escolaridade do professor. Quando o profissional em sala de aula possui nível superior, o desempenho dos alunos é maior. (FIALHO; MOURA, 2005). Para Gasque e Tescarolo (2010), alguns dos maiores desafios para a implementação do letramento informacional na educação básica está na formação inadequada dos professores e na ausência de infraestrutura de informação adequada. Para os professores, a atualização constante é fundamental em face das transformações econômicas, políticas, sociais e culturais que têm ocorrido aceleradamente nas últimas décadas. É necessário um processo de formação continuada para auxiliar os alunos a lidarem com grandes quantidades de informação.

Em relação à infraestrutura básica de informação,

pressupõe-se que o acesso à informação em seus diversos suportes e canais (TV, internet, DVDs, livros, revistas e jornais) e o ambiente apropriado à aprendizagem são condições sinequa non para inserção na sociedade da aprendizagem. Entretanto, um dos recursos mais utilizados na escola é o livro didático. (GASQUE; TESCAROLO, 2010, p. 51).

Ainda segundo os autores, um dos motivos que parece explicar o maior uso do livro didático nas escolas está no fato de que todo professor tem seu acervo de livros distribuídos gratuitamente pelas editoras, condição que o deixa acessível quando necessário. Além disso, os alunos muitas vezes se deparam com estruturas precárias, acervo obsoleto, recursos insuficientes e um sistema de serviços impropriamente chamado de biblioteca escolar.

A escolarização fundamental básica, com boa infraestrutura de recursos humanos e financeiros e com projeto pedagógico que privilegie a competência em informação será também grande aliada na formação do pesquisador juvenil, permitindo, inclusive, que ele chegue ao nível superior mais habilitado para a realização de pesquisas. Por isso, o desenvolvimento em habilidades informacionais seria mais efetivo se fosse praticado continuamente, desde as séries iniciais do Ensino Fundamental, com metodologias adequadas a cada fase (FIALHO; MOURA, 2005).

Fialho e Moura (2005, p. 205) ressaltam também a importância da participação da família na colaboração da pesquisa escolar: "oferecer ao filho uma educação de boa qualidade, assim como possibilitar o acesso às fontes de informação são maneiras importantes de participação da família”. As autoras ainda pontuam que os alunos demonstram satisfação em comunicar os resultados de suas pesquisas por meio de feiras científicas promovidas pela escola, por exemplo. 
No contexto de envolvimento da educação com o processo de construção da competência em informação, não se pode esquecer também do papel dos bibliotecários. Embora alguns se considerem educadores, nem sempre as escolas ou faculdades aos quais estão vinculados, e mesmo seus colegas de trabalho consideram-nos aptos para tal função. Embora seja sabido que as coleções das bibliotecas sejam essenciais para a formação estudantil, a educação para o domínio da informação acaba por ficar em segundo plano (DUDZIAK, 2003).

Segundo Dudziak (2003, p. 33), "a verdadeira mediação educacional ocorre quando o bibliotecário convence o aprendiz de sua própria competência, incutindo-lhe autoconfiança para continuar o aprendizado, transformando-o em um aprendiz autônomo e independente".

Para Fialho e Moura (2005), juntamente aos professores, os bibliotecários são parte necessária do desenvolvimento de competência em informação. No contexto escolar, o desenvolvimento das habilidades informacionais deve se pautar em uma parceria entre professores e bibliotecários para que, juntos, possam planejar, implementar e avaliar o processo de ensino-aprendizagem.

O bibliotecário pode, por exemplo, procurar atividades on-line para os professores explorarem com os alunos. Os professores podem também elaborar atividades em papel que terão sua implementação auxiliada pelo bibliotecário, especialista em tecnologia. Dessa forma, além de todos aprenderem, a biblioteca vai aumentando seus recursos. É importante ressaltar, entretanto, que nem todos os alunos podem ser considerados "nativos digitais": os que não nasceram num meio que os rodeassem de tecnologia por fazerem parte de meios menos favorecidos precisam ter atenção particular por meio de atividades na biblioteca que os auxiliem na inclusão digital, permitindo que se sintam conectados (CARVALHO, 2009).

Não só no quesito tecnológico as bibliotecas têm interferência positiva no processo de inclusão e de aprendizado. Para Fialho e Moura (2005), a existência e a utilização efetiva da biblioteca, por exemplo, faz diferença no aprendizado por aumentar a média de proficiência de leitura dos alunos que fazem uso deste espaço.

Dessa forma, numa junção entre uma efetiva inclusão digital e o aperfeiçoamento da leitura proporcionados pelo uso dos recursos oferecidos pelas bibliotecas, torna-se possível estimular um processo de aprendizagem autônomo, de "aprender a aprender". Nas palavras de Gasque e Tescarolo (2010, p. 53), "assim, entende-se que aprender é mais do que armazenar, memorizar e processar dados. Na verdade, aprender implica buscar e usar informações, utilizando os incontáveis recursos à disposição".

Em outras palavras, o efetivo aprendizado está relacionado com o montante de recursos educativos de que os sujeitos dispõem durante o processo de busca e uso de informações. A este montante dá-se o nome de "capital cultural", que será abordado a seguir.

\section{SUJEITOS, CAPITAL CULTURAL E ESCOLARIZAÇÃO}

A necessidade de informação varia de indivíduo para indivíduo, de acordo com seus capitais (cultural, econômico, social, entre outros) (SERRANO; STRANG, 2015). Nesse direcionamento, Bourdieu (1986) afirma que os capitais cultural e econômico são pré-requisitos para a definição de gostos e preferências. Estes, por sua vez, dizem muito sobre quem somos.

Ainda para Bourdieu (2007c), o capital simbólico se constitui pelo prestígio que o indivíduo possui, enquanto o capital cultural corresponde a uma somatória de saberes e conhecimentos acumulados ao longo da vida e dos capitais recebidos pelos antepassados, o também chamado capital cultural herdado. Sobre este capital, especificamente, Bourdieu (2007b) afirma que ele se expressa por meio de três estados: capital cultural incorporado, capital cultural objetivado e capital cultural institucionalizado. 0 primeiro, incorporado, relaciona-se às habilidades de falar, pensar e agir de cada indivíduo; no objetivado encontramse os bens culturais materiais, como viagens, livros e obras de arte e, no institucionalizado, o capital cultural se forma através de conhecimentos que se consolidam sob a forma de títulos ou diplomas.

0 capital cultural envolve, ainda, entre outros elementos, as habilidades e conhecimentos gerados através do núcleo familiar. Este tipo de capital é transmitido por herança e acumulado por meio de investimentos. 0 capital de maior valor são os encontrados em famílias de classes mais altas, devido ao fato de serem mais bem aparelhadas e terem acesso a equipamentos culturais (BOURDIEU, 2007a).

Conforme Serrano e Strang (2015, p. 152), "o capital cultural é o que mais interfere no sistema escolar, especialmente porque ele é desigualmente distribuído entre as classes".

Supunha-se, até a década de 1960, que a escola pudesse diminuir essa desigualdade por meio do acesso à educação, garantindo oportunidades iguais entre todos os cidadãos (NOGUEIRA; NOGUEIRA, 2002). Para os autores, o que Bourdieu propõe nos anos 1960 é uma forte relação entre desempenho escolar e origem social. Na escola, onde se via igualdade de oportunidades e meritocracia, Bourdieu passa a ver uma das principais instituições legitimadoras de privilégios sociais. Os autores acrescentam: 
Em primeiro lugar, a posse de capital cultural favoreceria o desempenho escolar na medida em que facilitaria a aprendizagem dos conteúdos e códigos escolares. As referências culturais, os conhecimentos considerados legítimos (cultos, apropriados) e o domínio maior ou menor da língua culta, trazidos de casa por certas crianças, facilitariam o aprendizado escolar na medida em que funcionariam como uma ponte entre o mundo familiar e a cultura escolar. A educação escolar, no caso das crianças oriundas de meios culturalmente favorecidos, seria uma espécie de continuação da educação familiar, enquanto para as outras crianças significaria algo estranho, distante ou mesmo ameaçador. (NOGUEIRA; NOGUEIRA, 2002, p. 21).

A frequência de ida a museus, por exemplo, aumenta consideravelmente à medida que se eleva o grau de instrução e corresponde a um modo de ser quase exclusivo às classes cultas, além disso, "a idade média dos visitantes de um museu aumenta à medida que se sobe na hierarquia social, o que parece indicar que o efeito da ação escolar é tanto mais duradouro quanto mais elevado é o nível escolar atingido" (BOURDIEU; DARBEL, 2007, p. 39). Esta ação, então, seria exercida de forma mais prolongada e todo aquele que a suportou disporia de maior competência, adquirida pelo contato precoce com obras de arte. "Sabe-se que este contato é sempre mais frequente à medida que se sobe na hierarquia social" (BOURDIEU; DARBEL, 2007).

Considerando que a "necessidade cultural" reduplica à medida que é satisfeita, a falta de prática acaba por ocultar este sentimento de privação. Esta necessidade, diferentemente das "necessidades básicas", é fruto da educação e, portanto, as desigualdades diante de obras de cultura são um aspecto das desigualdades diante da escola. Todas as atitudes de um visitante em relação a uma obra de museu, por exemplo, estão associadas quase exclusivamente aos diplomas obtidos e à duração da escolaridade (BOURDIEU; DARBEL, 2007).

Bourdieu considera ainda que é arbitrário o valor concedido à cultura consagrada transmitida pela escola. Apesar de arbitrária, ela é considerada como legítima e universalmente válida. Tal arbitrário cultural corresponde à força da classe social que o sustenta, ou seja, os valores considerados como legítimos são os sustentados pela classe dominante. Para Bourdieu, a cultura escolar seria imposta como legítima pelas classes dominantes (NOGUEIRA; NOGUEIRA, 2002).

Assim também o acesso aos "juízos de gosto" seriam efeito da instrução recebida: "a liberdade de se libertar das restrições escolares pertence apenas àqueles que assimilaram suficientemente a cultura escolar para interiorizar a atitude autonomizada em relação a essa cultura" (BOURDIEU; DARBEL, 2007, p. 93).

Dessa forma, a cultura ensinada pela escola é tão impregnada de valores das classes dominantes que ela mesma retoma a desvalorização mundana das práticas escolares. Apenas uma ínfima minoria de homens cultos consegue "se livrar" da cultura estereotipada da escola e adquirir uma cultura autêntica, liberta dos discursos escolares. "A plena posse da cultura escolar é a condição da superação da cultura da Escola em direção à cultura livre", considerada pela classe burguesa como "o valor dos valores" (BOURDIEU; DARBEL, 2007, p. 93).

Apesar de vinculada a uma classe, a cultura escolar precisaria ser apresentada como neutra. Dessa forma, uma vez reconhecida como legítima e neutra, poderia exercer sua função de legitimadora de desigualdades sociais (NOGUEIRA; NOGUEIRA, 2002)

para que sejam favorecidos os mais favorecidos e desfavorecidos os mais desfavorecidos, é necessário e suficiente que a escola ignore, no âmbito dos conteúdos do ensino que transmite, dos métodos e técnicas de transmissão e dos critérios de avaliação, as desigualdades culturais entre as crianças das diferentes classes sociais. (BOURDIEU, 2007b, p. 53).

Nesse sentido, nas palavras de Nogueira e Nogueira (2002, p. 29), "tratando formalmente de modo igual, em direitos e deveres, quem é diferente, a escola privilegiaria, dissimuladamente, quem, por sua bagagem familiar, já é privilegiado".

0 argumento de Bourdieu se baseia no fato de que a comunicação pedagógica, assim como qualquer outra comunicação cultural, exige que os receptores dominem o código usado nessa comunicação, ou seja, o grau em que é compreendida pelos alunos depende do seu grau de domínio do código. Esse grau de domínio do código, por sua vez, varia de acordo com a distância entre o arbitrário cultural apresentado pela escola e a cultura familiar de origem dos alunos, pois a comunicação pedagógica exige o domínio prévio de 
um conjunto de habilidades que apenas os membros das classes superiores possuiriam (NOGUEIRA; NOGUEIRA, 2002).

As diferenças nos resultados escolares dos alunos, portanto, teriam uma tendência a serem vistas como diferenças de capacidade, enquanto na realidade seriam resultado das diferenças de distância entre a cultura escolar e a cultura familiar do aluno (NOGUEIRA; NOGUEIRA, 2002).

Com relação a esse aspecto, nas palavras de Serrano e Strang (2015, p. 151), "a herança cultural e o êxito escolar estão profundamente conectados, já que os resultados obtidos na trajetória escolar dizem muito sobre as propriedades culturais cultivadas dentro do contexto familiar".

É possível constatar fortes variações nas práticas culturais de indivíduos de mesmo nível escolar ou social devido ao nível cultural de sua família de origem. Isso mostra que o processo de aculturação separa indivíduos aparentemente iguais no que diz respeito à situação social e nível escolar (BOURDIEU; DARBEL, 2007). Os autores exemplificam, em relação ao mundo da arte, o reforço da desigualdade social cometido no âmbito escolar e a influência da cultura familiar:

A existência de uma relação tão forte entre o nível de instrução e a prática cultural não deve dissimular que, considerando os pressupostos implícitos que a comandam, a ação educativa do sistema escolar tradicional só pode alcançar toda a sua eficácia enquanto se exercer sobre indivíduos previamente dotados, pela educação familiar, de uma certa familiaridade com o mundo da arte: daí, seguese que a ação da Escola - exercida de forma bastante desigual (nem que fosse no que diz respeito à duração) sobre as crianças oriundas das diferentes classes sociais e que não é bem-sucedida senão de forma bastante desigual junto àqueles que ela atinge - tende, pelo menos em países como a França ou a Holanda, a reduplicar e consagrar, por suas sanções, as desigualdades iniciais diante da cultura. Assim, considerando que a parcela daqueles que receberam da família uma iniciação precoce cresce consideravelmente com o nível de instrução, o que é possível identificar através do nível de instrução limita-se a ser o acúmulo dos efeitos da formação adquirida no seio da família com as aprendizagens escolares, por sua vez, pressupostas por tal formação. (BOURDIEU; DARBEL, 2007, p. 54).

Em síntese, sobre a influência da cultura no desempenho escolar, Bourdieu (2007c) acredita que a chave para o sucesso ou o fracasso na escola está no patamar cultural da família e que quanto maior este for, mais rico será o aporte de cultura e de conhecimento de um indivíduo.

Já em um sentido mais pragmático, as vivências do sujeito permitem constante renovação do capital social e do cultural, além de permitir uma agregação de habilidades e competências. Isso fica evidente, por exemplo, na escolha das fontes informacionais e na forma de processar, usar e absorver as informações encontradas (BOURDIEU, 2007b). Também devido a este sentido mais pragmático, não se pode dizer que o diploma é um indicador irrepreensível do nível cultural, já que não leva em consideração determinados conhecimentos adquiridos de forma autodidata, por exemplo. Determinadas diferenças entre o nível cultural dos sujeitos ainda podem ocorrer devido à exposição a uma formação clássica, como o acesso aos estudos de latim, por exemplo. (BOURDIEU; DARBEL, 2007).

Bourdieu e Darbel (2007) salientam também a influência de outros fatores que variam mesmo que os conhecimentos adquiridos na escola e a posse de um diploma sejam formalmente equivalentes: o conteúdo do ensino, o método pedagógico, o recrutamento social dos docentes e discentes e o modo de atribuição dos diplomas são alguns destes fatores.

Assim, o capital cultural se multiplica, transformando-se em competências. Estas, por sua vez, irão favorecer o sujeito no sentido de alcançar um nível mais elevado de escolaridade ou se tornar profissionalmente mais qualificado que outros. Em outras palavras, o capital cultural pode ter uma estreita relação com aspectos da educação formal e não formal (SERRANO; STRANG, 2015).

Para apreender a "informação" proposta por uma obra artística, por exemplo, cada indivíduo possui uma capacidade definida e limitada pelo seu conhecimento global (por sua vez, dependente de sua educação e de seu meio).

Quando a mensagem excede as possibilidades de apreensão do espectador, este não apreende sua "intenção" e desinteressa-se do que lhe parece ser uma confusão sem o menor sentido.

Para, por exemplo, realizar uma boa pesquisa científica pressupõe-se competência em informação e capital cultural do sujeito, pois o desenvolvimento satisfatório depende do uso eficiente dos instrumentos informacionais. Esta teoria se confirma na biblioteca universitária, quando geralmente os estudantes que mais utilizam os recursos informacionais são justamente aqueles provenientes de famílias com capital cultural mais alto ou que tenham sido orientados por professores, reconhecidamente detentores de elevado 
capital cultural e social. "Assim, quanto maior o nível de capital cultural, maior a probabilidade de elevação do capital informacional" (SERRANO; STRANG, 2015, p. 153)

\section{CONSIDERAÇÕES FINAIS}

Tanto as definições e reflexões sobre competência em informação apresentadas quanto os objetivos gerais para uma política de competência em informação no Ensino Fundamental, descritos pelos Parâmetros Curriculares Nacionais (PCNs), nos remetem à estreita relação entre o conceito de competência em informação e instituições de ensino.

Sobre esta relação, é possível retomar Fialho e Moura (2005), para os quais a escolarização fundamental básica, com boa infraestrutura de recursos humanos e financeiros e com projeto pedagógico que privilegie a competência em informação é grande aliada na formação do pesquisador juvenil, permitindo, inclusive, que ele chegue ao nível superior mais habilitado para a realização de pesquisas.

Considerando que o desenvolvimento do domínio de tecnologias, o aprimoramento de métodos de pesquisa e a utilização de fontes de informação para adquirir conhecimento sejam ações desenvolvidas prioritariamente no âmbito escolar, é possível dizer que, à medida que aumentam os anos de estudos, desenvolve-se proporcionalmente o processo de competência em informação. Entretanto, este não é um processo neutro nem inerente à trajetória de todos os cidadãos, estando fortemente ligado ao capital cultural dos sujeitos.

Para Bourdieu (2007b), como já visto, o capital cultural corresponde ao conjunto de saberes e conhecimentos acumulados pelo indivíduo ao longo da vida. Esse capital cultural pode, inclusive, ser do tipo institucionalizado, adquirido por meio de títulos e diplomas. Títulos e diplomas que remetem ao sistema escolar, o qual, segundo Serrano e Strang (2015, p. 152), "sofre importante interferência do capital cultural, dado que este é desigualmente distribuído entre as classes".

Para Bourdieu (2007b), entretanto, não se pode considerar apenas o diploma como indicador irrepreensível do capital cultural: as vivências do sujeito e mesmo conhecimentos adquiridos de maneira autodidata podem renovar e agregar habilidades e competências, como as habilidades na escolha de fontes de informação e no uso das informações encontradas. A elevação no nível de capital cultural, nesses casos, eleva também o nível de capital informacional.

Em outras palavras, há capital cultural mesmo na ausência de títulos e diplomas, e haverá disparidades quanto às habilidades informacionais mesmo entre sujeitos que se encontram no mesmo nível de escolaridade. 0 nível de capital cultural influencia na competência em informação, assim como é possível concluir que à medida que se aumenta o acesso a fontes de informações confiáveis e as necessidades informacionais são supridas os sujeitos adquirem conhecimento e possibilitam elevar seu capital cultural.

Num cenário ideal, portanto, indivíduos teriam acesso a escolas dotadas de recursos humanos, financeiros e de infraestrutura, além de um projeto curricular, voltados para o desenvolvimento de sua competência em informação, permitindo, assim, a aquisição de conhecimentos e consequentemente elevação de seu capital cultural. Como as necessidades culturais reduplicam à medida que são satisfeitas (BOURDIEU; DARBEL 2007), este seria um processo de retroalimentação constante, em que o sujeito eleva seu capital cultural passando a ter mais "sede" por conhecimento e continua aprimorando suas habilidades informacionais na busca e uso de fontes de informação confiáveis, aumentando, também, sua competência em informação.

Escolarização, capital cultural e competência em informação formariam, assim, uma tríade de grande influência no processo de desenvolvimento social dos sujeitos.

\section{REFERÊNCIAS}

AMERICAN LIBRARY ASSOCIATION. ASSOCIATION OF COLLEGES AND RESEARCH LIBRARIES. Information literacy competency standards for higher education. Chicago, 2000. Disponível em:< https://alair.ala.org/bitstream/handle/11213/7668/ACRL\%20Information\%20Literacy\%20Competency \%20Standards\%20for\%20Higher\%20Education.pdf?sequence=1\&isAllowed=y $>$. Acesso em: 10 marc. 2016.

BOURDIEU, P. The formsof capital. In: RICHARDSON, J. (Comp.). Handbook of theory and research for thesociology of education. New York: Greenwood, 1986. Disponível em:<https://www.marxists.org/reference/subject/philosophy/works/fr/bourdieu-forms-capital.htm>. Acesso em: 12 abr. 2016. 
BOURDIEU, P.; DARBEL, A. O amor pela arte - os museus de arte na Europa e seu público. São Paulo: Editora da Universidade de São Paulo, 2007; Porto Alegre: Zouk, 2007.

BOURDIEU, P. A distinção: crítica social do julgamento. São Paulo; Porto Alegre: EDUSP; Zouk, 2007a.

BOURDIEU, P. Escritos de educação. Petrópolis, Rio de Janeiro: Vozes, 2007b.

BOURDIEU, P. A economia das trocas simbólicas. São Paulo: Perspectiva, 2007c.

BRASIL. Ministério da Educação. Secretaria de Educação Média e Tecnológica. Parâmetros curriculares nacionais: ensino médio. Brasília: MEC, 2000. Disponível

em:<http://portal.mec.gov.br/seb/arquivos/pdf/blegais.pdf>. Acesso em: 9 mar. 2016.

BRASIL. Ministério da Educação. Secretaria de Educação Fundamental. Parâmetros curriculares nacionais: introdução aos parâmetros curriculares nacionais. Brasília: MEC/SEF, 1997. Disponível em:<http://portal.mec.gov.br/seb/arquivos/pdf/livro01.pdf>. Acesso em: 9 mar. 2016.

CAMPELLO, B. 0 movimento da competência informacional: uma perspectiva para o letramento informacional. Ci. Inf., Brasília, v. 32, n. 3, p. 28-37, 2003. Disponível em $<$ http://bogliolo.eci.ufmg.br/downloads/CAMPEL0\%20Competencia\%20Informacional.pdf $>$ Acesso em 10 mar. 2016

CARVALHO, A. A. Aprender e ensinar na era digital: o papel da biblioteca escolar. 2009. Disponível em $<$ http://files.celestebecoura.webnode.pt/200000022649f2668a8/aprender\%20ensinar\%20na\%20era\%2020digital.pdf> Acesso em 10 mar. 2016

DUDZIAK. E. A. Informationliteracy: princípios, filosofia e prática. Ci. Inf., Brasília, v. 32, n. 1, p. 23-35, 2003. Disponível em:<http://webcache.googleusercontent.com/search?q=cache:8vRbdHqp7VMJ:revista.ibict.br/ciinf/artic le/download/1016/1071+\&cd=1\&hl=pt-BR\&ct=clnk\&gl=br $>$ Acesso em: 26 fev.2016.

FIALHO, J. F.; MOURA, M. A. A formação do pesquisador juvenil. Perspect. Ciênc. Inf., Belo Horizonte, v 10, n. 2, p. 194-207, 2005. Disponível em

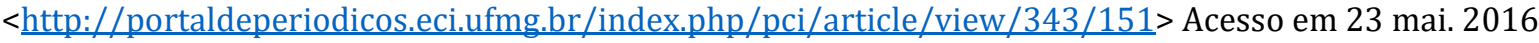

FORD, B. J. Information Literacy as a Barrier. IFLA GENERAL CONFERENCE, 60., 1994. Havana. Proceedings...Havana, 1994. Disponível em:<https://archive.ifla.org/IV/ifla60/60-forb.htm >.Acesso em: 10 mar. 2016.

GASQUE, K. C. G. D. Letramento informacional: pesquisa, reflexão e aprendizagem. Brasília: Universidade de Brasília, 2012.

GOMES, A. S. L. Letramento científico: um indicador para o Brasil. São Paulo: Instituto Abramundo, 2015. Disponível em:<http://acaoeducativa.org.br/wpcontent/uploads/2014/10/ILC Letramentocientifico um-indicador-para-o-Brasil.pdf> Acesso em: 24 maio 2016.

GRUPO BANCO MUNDIAL. Relatório sobre o desenvolvimento mundial 2016: dividendos digitais. Washington DC, Grupo Banco Mundial, 2016. Disponível em <http://www.wds.worldbank.org/external/default/WDSContentServer/WDSP/IB/2016/01/13/090224 b08405ea05/2 0/Rendered/PDF/World0developm0000digital0dividends.pdf> Acesso em: 1 jun. 2016.

LE COADIC, Y. F. A ciência da informação. Brasília, DF: Briquet de Lemos/Livros, 1996. Disponível em:<http://www.ebah.com.br/content/ABAAAgu3YAI/a-ciencia-informacao > Acesso em: 12 abr. 2016.

NOGUEIRA, C. M. M.; NOGUEIRA, M. A. A sociologia da educação de Pierre Bourdieu: limites e contribuições. Educação \& Sociedade, n. 78, 2002. Disponível em $<$ http://www.scielo.br/pdf/es/v23n78/a03v2378> Acesso em 10 abr. 2016 
PERRENOUD, P. Dez novas competências para ensinar: convite à viagem. Porto Alegre: Artmed, 2000. Disponível em:<http://abenfisio.com.br/wp-content/uploads/2016/06/10-novas-competencias-paraensinar.pdf $>$. Acesso em: 12 abr. 2016.

SERRANO, J. F. S.; STRANG, B. L. S. O capital cultural de estudantes universitários determina sua competência informacional? R. Educação Online, n. 20, p. 146-171, 2015. Disponível em:<http://educacaoonline.edu.puc-rio.br/index.php/eduonline/article/view/202>. Acesso em: 12 abr. 2016.

SILVA et al. Inclusão digital e educação para a competência informacional: uma questão de ética e cidadania. Ci. Inf., Brasília, v. 34, n.1, p. 28-36, 2005. Disponível em $<$ http://www.scielo.br/pdf/ci/v34n1/a04v34n1.pdf> Acesso em 10 mar. 2016

SIQUEIRA, I. C. P. Pressupostos para um programa nacional de competências informacionais. Ci. Inf., Brasília, v. 40, n. 3, p. 478-491, 2011. Disponível em <http://revista.ibict.br/ciinf/index.php/ciinf/article/view/1953/1443> Acesso em 23 mai. 2016

TARAPANOFF, K.; SUAIDEN, E.; OLIVEIRA, C. L. Funções sociais e oportunidades para profissionais da informação. DataGramaZero, v. 3, n. 5, 2002. Disponível em: $<$ http://repositorio.unb.br/bitstream/10482/884/1/ARTIGO FuncoesSociaisOportunidadesProfissio nais.pdf $>$. Acesso em: 12 abr. 2016.

Editores do artigo: Enrique Muriel-Torrado, Edgar Bisset Alvarez, Camila Barros. 